\title{
Research on Wind Disaster Accident of Port Crane
}

\author{
Bin Zhang ${ }^{1, *}$, Yao-ting Tong ${ }^{2}$, Li Qin ${ }^{3}$, Zheng-qiu Huang ${ }^{2}$ \\ ${ }^{1}$ Shanghai Fengxian District Special Equipment Inspection Institute, Shanghai 201406 \\ ${ }^{2}$ Shanghai Institute of Special Equipment Inspection and Technical Research, Shanghai, 200062 \\ ${ }^{3}$ Shanghai PudongNew Area Special Equipment Inspection Institute, Shanghai, 201210
}

\begin{abstract}
Gust is the most serious natural disaster that threatens the safety of port portal crane. The wind resistance of some port cranes is not optimistic, and wind disaster accidents occur frequently. Based on the analysis of some classic cases of wind disasters at home and abroad, this paper finds out the weak links of the wind proof ability of port portal crane, and puts forward the countermeasures to improve and enhance the wind proof ability of port portal crane.
\end{abstract}

\section{Introduction}

As we all know, due to the special geographical location of the port along the river and the coast, the port crane has become the direct target of strong typhoon, tornado and gust above level 7 .

As the number of port portal cranes continues to increase, crane equipment is also developing in the direction of large-scale and high-efficiency. These changes in cranes have also led to an increase in port portal cranes' overall dimensions, windward area, working wind load, and the height of the wind force center. However, the large size of the crane is not enough to cope with sudden gale disasters. Strong winds can cause crane damage, especially sudden gusts, which are unpredictable and difficult to prevent. It is one of the biggest hidden dangers to port production safety, which can cause personnel and property. Because of heavy losses, it is necessary to strengthen the wind-proof and safety work of port portal cranes.

Generally, the main reasons for the wind disaster accidents of port portal cranes are formed by the following aspects:

1) The wind-proof standards of port portal cranes are different and change ${ }^{[1]}$, For example, the standards of different regions and different times are also different. Some port portal cranes put into use in the early stage cannot reach the design wind protection capacity specified in the current design standards, and the design standards based on the design calculations of different design manufacturers are also different;

2) There are differences between the actual state of the wind proof braking device and the design capacity of the braking device of the port portal crane;

3) The operation management personnel do not pay enough attention to safe production, violate safe operation or loose management.

\section{Accident case analysis}

In recent years, the annual growth rate of the number of domestic hoisting machinery has basically remained above $2.5 \%$, as shown in Figure 1.

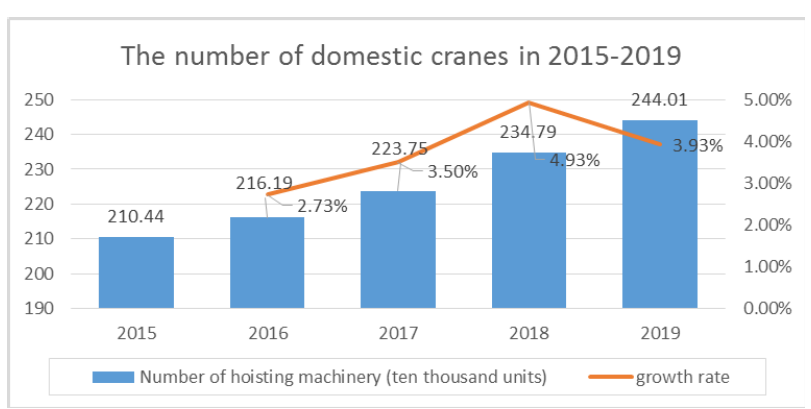

Figure 1. The number of domestic cranes in 2015-2019

During 2015-2019, a total of 392 crane accidents occurred in China. According to the statistical results of Table 1, the accident rate of 10,000 cranes and equipment in China from 2015 to 2019 is shown in Figure 2.

Table 1. Accident rate of 10,000 hoisting machinery and equipment

\begin{tabular}{|c|c|c|c|}
\hline Years & $\begin{array}{c}\text { Number of } \\
\text { hoisting } \\
\text { machinery (ten } \\
\text { thousand units) }\end{array}$ & $\begin{array}{c}\text { Number } \\
\text { of crane } \\
\text { accidents }\end{array}$ & $\begin{array}{c}\text { Accident rate } \\
\text { of } 10,000 \\
\text { hoisting } \\
\text { equipment }\end{array}$ \\
\hline 2015 & 210.44 & 79 & 0.37 \\
\hline 2016 & 216.19 & 94 & 0.43 \\
\hline 2017 & 223.75 & 93 & 0.42 \\
\hline 2018 & 234.79 & 100 & 0.43 \\
\hline 2019 & 244.01 & 26 & 0.11 \\
\hline
\end{tabular}




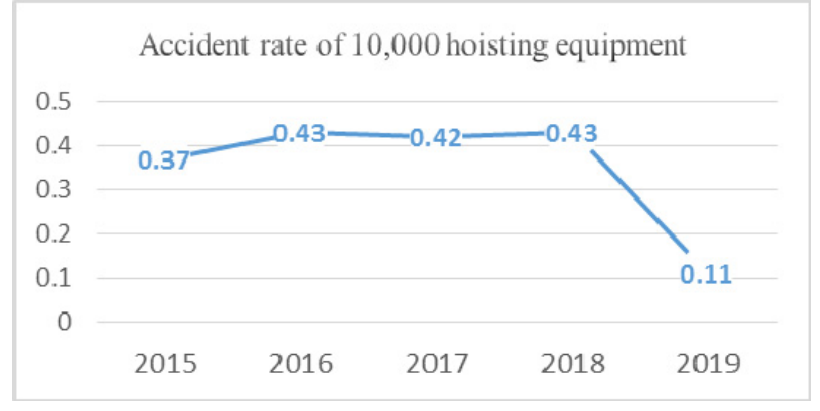

Figure 2. Accident rate of 10,000 hoisting equipment

Crane brings convenience, quickness, flexibility and high efficiency to production. At the same time, accidents occur frequently due to unsafe factors of equipment itself. In particular, the environmental conditions of the port portal crane are complex and harsh, and the stress state is complex. A little negligence will lead to accidents such as falling objects to hurt people and the whole machine overturning.

\subsection{Typical accident case}

\subsubsection{Case 1}

In May 1973, in Lu County, Shaanxi Province, wind speed $17.1 \mathrm{~m} / \mathrm{s}$, and the portal crane (10t) seriously twisted the main beam and the upper and lower beams under the non-working state. The accident process was as follows: the crane blew about 90 meters along the wind direction, the rigid outrigger was blocked by the object, it was inclined after sliding out, and the flexible outrigger slipped out of the track and overturned. The main reason is: the rail clamp is out of order, which causes the equipment to slide under the wind.

\subsubsection{Case 2}

In July 1980, Beilun Port, Ningbo, wind speed 20m/s, portal crane (10t), the pull rod in the non-working state broke, the main reason is that the section strength of the crane design does not meet the actual requirements, which causes the equipment tie rod to break under the action of wind load.

\subsubsection{Case 3}

In April 1984, Xiamen Port, with a wind speed of 46m/s and a portal crane (10t), the outriggers were severely twisted and deformed under non-working conditions. The accident process was as follows: the equipment was blown away under strong wind conditions and gradually accelerated, hit the windproof iron shoes, the outriggers damaged the windproof iron shoes, and fell from the trolley. The main cause of the accident was: incomplete crane safety protection devices, no buffers, rail clamps, etc.

\subsubsection{Case 4}

In September 1991, Nagasaki Port, Japan, wind speed $55 \mathrm{~m} / \mathrm{s}$, portal crane (10t), under non-working conditions, the legs were severely twisted and deformed, and the whole machine overturned; eight cranes without anchoring devices overturned and collapsed. The accident was as follows: after the typhoon landed, the cranes were fixed with $\mathrm{T}$-shaped structural anchoring devices. After the typhoon came, the inclined rods of 2 crane trusses were deformed, the anchoring devices of 4 cranes were destroyed and the whole machine overturned, and 8 cranes without anchoring devices overturned and collapsed. The main reason is: the lack of anti-wind and anti-skid devices of some equipment or insufficient wind resistance.

\subsubsection{Case 5}

In September 1996, at Zhanjiang port, Guangdong Province, the wind speed was $57 \mathrm{~m} / \mathrm{s}$ and the portal crane (10t) fell into the sea under non-working conditions. In this accident, the running wheel is not rolling, but sliding with the track at a high speed. The crane is driven into the sea because its anti-typhoon device is not enough to resist the strong wind force. The designed anti wind capacity of the port crane in our country is grade 11 . Due to the low anti wind standard, it is not enough to prevent the typhoon from harming the crane.

\subsubsection{Case 6}

In August 2009, Jiading, Shanghai, wind speed 40m/s, portal crane $(10 \mathrm{t})$, derailed and capsized under nonworking conditions. The main reason is the equipment defect: the crane's service brake is not adjusted to the effective working state according to the specified requirements, so that the crane has no braking force when the crane is initially moved; the crane rail clamp has no operation direction mark, which is easy to cause the operator to make mistakes or delay the operation time; The crane track is not provided with a track terminal stop device to make the crane slide out of the track.

\subsubsection{Case 7}

In April 2016, there was a sudden gust of wind (later determined to be 11 gusts) in Dongguan Port, Guangdong. The portal crane was blown by sudden gusts of wind on site and slipped along the track under working conditions, and finally hit the stop device. Workers' residential areas caused huge casualties and the entire machine overturned. The main reasons are: improper operation by the on-site staff, the crane in the stopped operation state did not strictly implement the operating procedures, and all the wind-proof and antiskid devices were activated within the effective time. 


\subsection{Accident investigation summary}

\subsubsection{Design standards are lower than actual requirements}

According to GB 6067 "Safety Regulations for Cranes" ${ }^{[2]}$, when the wind level is greater than 7, the cranes working along the coast such as portal cranes should stop working and anchor the crane.

In the crane design standard, the minimum wind speed required at present is $55 \mathrm{~m} / \mathrm{s}$. However, the coastal geography and climate conditions in different regions of China are different, so the wind protection standard cannot meet the requirements of crane. According to accident case $4^{[3]}$, the sustained wind of this accident is $>50 \mathrm{~m} / \mathrm{s}$, gust is $>57 \mathrm{~m} / \mathrm{s}$, and the maximum wind speed of $65-70 \mathrm{~m} / \mathrm{s}$ is measured in Zhanjiang port, which is far more than the force 12 gale. Therefore, the improvement of wind force standard of crane windproof design has a great impact on the windproof performance of crane.

\subsubsection{Device body defect}

One of the most important safety measures of crane is windbreak, windbreak, anchor rail, windbreak. Windproof safety devices can be used alone or in combination. The selection and configuration of crane safety devices are different in various enterprises. Generally speaking, when the crane leaves the factory, the windproof ability basically meets the windproof requirements. With the crane working life getting longer, many windproof devices have aging or hidden danger if they can't be repaired in time if the device fails, it is easy to cause safety accidents.

In the gusty working state, the brake and rail clamp are used most frequently, so the performance of their safety devices is also the most important. According to the principle of force synthesis and decomposition, the windproof performance of the whole crane is the superposition of the windproof capacity values of each windproof device. According to the experimental data, the contribution value of the crane's brakes against wind accounts for about $20 \%$ of the crane's anti-skid and wind resistance. Therefore, the defects of the brakes and rail clamps are one of the important factors that cause accidents; the failure to timely and effective use or lack of anti-wind and anti-skid device is also an important factor causing the accident. In the gust state, the relevant operators should respond quickly, otherwise the equipment is easy to cause the accident due to the lack of effective braking device.

\subsubsection{Security management}

The working site of port portal crane is complex, such as operators who violate the rules and regulations, will also cause huge loss and safety accidents. For example: the operator is not concentrated or operates against the rules when working, and the safety accidents of crane windproof are often related to the illegal operation of the staff. The reasons include: the enterprise does not have relevant wind safety training, the operators do not understand the wind safety measures; the enterprise does not have relevant operation examples, and the operators have no basis for operation. The main problems for staff: in the case of no work, the stop is not in accordance with the designated position, the windproof cable is not anchored and fastened in the case of strong wind, which leads to the loss of wind prevention capacity.

The imperfect rules and regulations and the lack of effective countermeasures are also the major hidden dangers of the accident, so the windbreak safety inspection system should be established as comprehensively as possible. It mainly includes safe operation; daily maintenance; wind-proof post responsibility system; regular inspection system; emergency plan; wind-proof drill; staff training and inspection, so that operators can better understand the knowledge of crane wind-proof safety.

\subsection{Wind load analysis}

The port crane suffered from tornadoes, gusts and typhoons. Among them, tornadoes and gusts belong to the category of sudden winds, and typhoons are also called hurricanes. Tornadoes and gusts are characterized by small area unpredictability, abruptness, randomness and short invasion process. The duration of sudden wind is usually $10-30$ minutes, and the wind speed changes sharply.

Sudden wind is a kind of strong convective weather, and the wind speed is more than $15 \mathrm{~m} / \mathrm{s}$; hurricane is a tropical cyclone with wind force equal to or greater than 12 (wind speed $32.7 \mathrm{~m} / \mathrm{s}$ ); sudden wind is one of the disastrous weather, because it is unpredictable in advance, it is very destructive and harmful.

Based on the harm of sudden wind, the dynamic anti sudden wind of crane is often set as level 3 in design, as follows ${ }^{[4]}$ :

Level 1: according to the regulations, when the wind force is greater than level 7, the coastal crane shall stop working. Therefore, the necessary wind speed $v>$ $17.1 \mathrm{~m} / \mathrm{s}$ is obtained (minimum requirement).

Level 2: based on the working wind speed designed by the manufacturer for large cranes, the standard wind speed $\mathrm{v}=20 \mathrm{~m} / \mathrm{s}$ (basic requirements) is determined.

Level 3: short term hurricane, when the wind reaches level 12 , that is, the wind speed $\mathrm{v}_{\max }=32.7 \mathrm{~m} / \mathrm{s}$ (limit requirement).

Although the crane is designed according to the crane related standards, but in the actual working environment and use, the wind load still has a huge impact on the crane. One is to increase the running resistance of the crane. In the daily design and calculation, it will be found that the operation resistance generated by the wind load acting on the crane structure is often greater than the friction; the second is that the wind can make the crane slip (or roll); the third is that the wind can make the crane overturn; and the fourth is that the local parts of the crane fail. 


\subsection{Evaluation index of windbreak capability}

Through the analysis of the main causes of the accident, the wind proof ability index of the equipment is summarized, as shown in Figure 3.

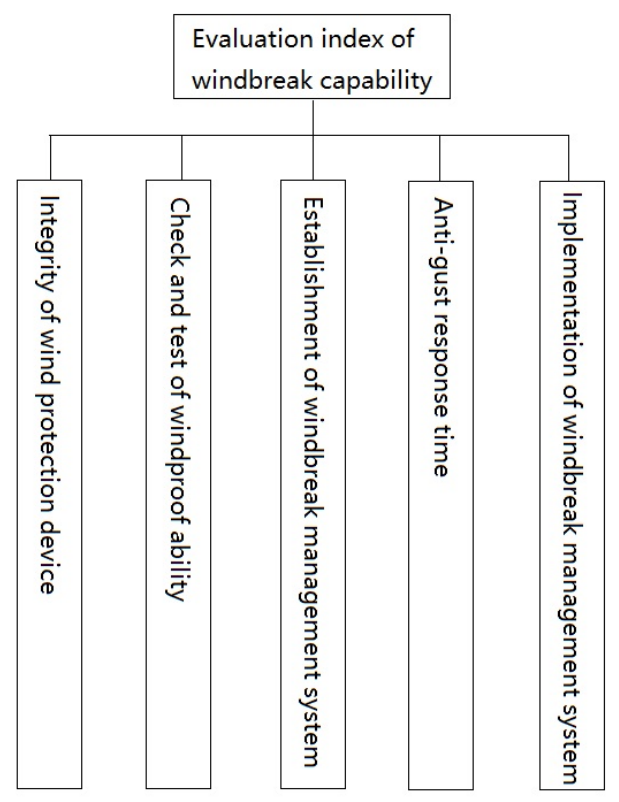

Figure 3. Schematic diagram of evaluation index composition of equipment windproof capability

\subsubsection{Integrity of wind protection device}

Check whether the equipment crane brake is equipped with wind proof device. The equipment is often equipped with brake, rail clamping device, rail jacking device, windproof iron shoes, windproof cable, anchoring device, etc. ${ }^{[5]}$ these devices can be used alone or in combination. Check whether the equipment is installed according to the requirements on site, and confirm that the device is intact and effective.

\subsubsection{Check and test of windproof ability}

According to the situation of the equipment, calculate the windproof ability of the equipment under working and non-working conditions, and confirm whether the windproof ability meets the requirements. For the equipment in doubt, the field test method can be used to test the windproof ability. If the evaluation result of the index is unqualified, the penalty function will be started, and the wind proof capability of the whole equipment will be unqualified.

\subsubsection{Establishment of windbreak management system}

Check whether the enterprise has established the relevant wind prevention management system (among which, the gust prevention management system is a required item), whether the wind prevention measures and responsible persons of the equipment under various working conditions are clear, and the measures formulated should be clear and operable.

\subsubsection{Anti-gust response time}

Send out strong gust warning signal, record the response situation and response time of equipment related management and operation personnel (in order to ensure the reliability of test results, the relevant personnel of a certain equipment should be randomly selected without informing) after encountering gust, judge whether they make the specified action quickly, and complete the gust prevention measures.

\subsubsection{Implementation of windbreak management system}

Check whether the enterprise conducts wind prevention management according to the system, and whether the enterprise conducts regular wind prevention emergency drills for important equipment and personnel.

\section{Conclusion}

In this paper, the portal crane, a typical port machinery, is taken as the research object. Through the study of accident cases, the evaluation index of wind protection ability is established. It is concluded that the occurrence of wind disaster accident of portal crane is determined by many factors. One part is the huge destructive force of wind load on the crane, and the occurrence time is uncertain and random. The other part mainly includes the following aspects through the analysis and research of the above factors, the solutions can be found out, which can greatly enhance the windproof ability of the crane. Although the wind disaster of the port portal crane is sudden and unpredictable, the design standards, windproof safety devices and windproof safety management can be continuously improved and implemented Practice, to help reduce unnecessary wind accidents.

\section{Acknowledgements}

I would like to express my sincere thanks to Shanghai Fengxian District Special Equipment Inspection Institute. With the help of my colleagues, I completed this paper.

Last my gratitude also extends to my family who have been assisting, supporting and caring for me all of my life.

\section{References}

1. Zhou Yuzhong, Hu Yuliang, et al. (2007) The current situation and countermeasures of wind-proof capability of port cranes in working condition. Baosteel Technology, 01: 41-44.

2. GB 6067-1985. (1985) Safety Regulations for Lifting Machinery. 
3. Zhang Meizhong. (2009) Causes and prevention of overturning of large port cranes in strong winds, Port Science and Technology, 03:16-20.

4. GB/T 28591-2012. (2012) Wind power rating.

5. Wang Gongxian. (2019) New windproof and antiskid device for crane. Lifting and transportation machinery, 12:57-62. 